\title{
P2X7 receptor involved in antitumor activity of atractylenolide I in human cervical cancer cells
}

\author{
Yue Han ${ }^{1} \cdot$ Can Bai ${ }^{2}$ Xi-Meng He ${ }^{2}$. Qing-Ling Ren ${ }^{1}$
}

Received: 31 October 2021 / Accepted: 10 February 2022 / Published online: 2 March 2022

(C) The Author(s) 2022

\begin{abstract}
Atractylenolide I (Atr-I) was found to sensitize a variety of human cancer cells in previous studies. Purinergic P2X7R plays important role in different cancers. However, whether Atr-I could generate antitumor activity in human cervical cancer cells and P2X7R get involved in this effect remain unclear. In this study, Hela (HPV 18+) and SiHa (HPV 16+) cells were treated with different doses of Atr-I. The results indicated that agonist and antagonist of P2X7 receptors, BzATP and JNJ-47965567 (JNJ), could suppress the proliferation of Hela and SiHa cells. Atr-I demonstrated a considerable antitumor effect in both human cervical cancer cells in vitro. Atr-I combined with P2X7R agonist, BzATP, restored Atr-I-induced growth inhibition in Hela cells but not in SiHa cells. However, the combinatorial treatment of P2X7R antagonist JNJ and Atr-I has an additive effect on cell growth inhibition in SiHa cells rather than in Hela cells. It implied that P2X7R would get involved in the antihuman cervical cancer cells effect of Atr-I.
\end{abstract}

Keywords Atractylenolide I $\cdot$ P2X7Rs $\cdot$ Hela cells $\cdot$ SiHa cells $\cdot$ Human cervical cancer cells

Yue Han is an associate Professor in the department of Gynecology, the Affiliated Hospital of Nanjing University of Chinese Medicine of China. Her research interrest is purinergic signalling and reproductive system diseases in women.

Qing-Ling Ren

yfy0047@njucm.edu.cn

Yue Han

hy19870705@sina.com

Can Bai

756218617@qq.com

Xi-Meng He

2944780253@qq.com

1 Department of Gynecology, The Affiliated Hospital of Nanjing University of Chinese Medicine, Nanjing 210029, China

2 Acupuncture \& Chronobiology Key Laboratory of Sichuan Province, Chengdu University of Traditional Medicine, Chengdu 610075, China

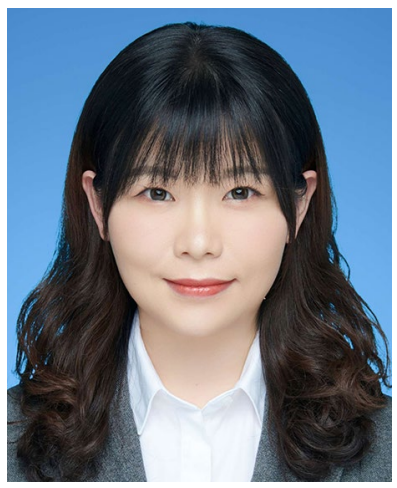

\section{Introduction}

Cervical cancer is the fourth most common cause of morbidity and mortality among women with gynaecologic malignancies worldwide, and there were an estimated 600,000 new cases and 340,000 deaths in 2020 [1]. A large majority of cervical cancer (more than 95\%) is due to the human papillomavirus (HPV) and HPV types 16 and 18 cause at least $70 \%$ of cervical cancers [2]. In the past few decades, despite the application of human papillomavirus (HPV) vaccine has been proven to dramatically reduce the risk of cervical cancer, the fact which cannot be neglected revealed that a high proportion of cervical cancer cases were clinically 
A<smiles>C=C1C2CC3CCC2(C)C[C@]1(C)C=C1OC(=O)C(C)=C1C3</smiles>

Atractylenolide I
B

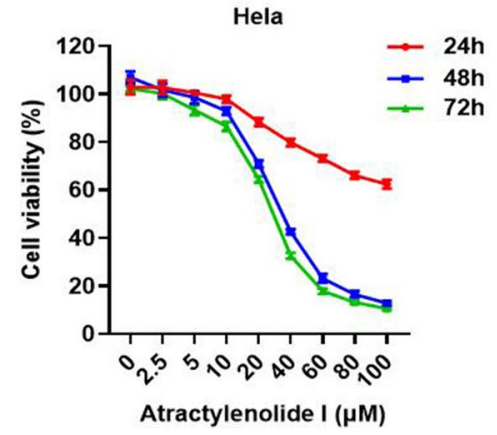

SiHa

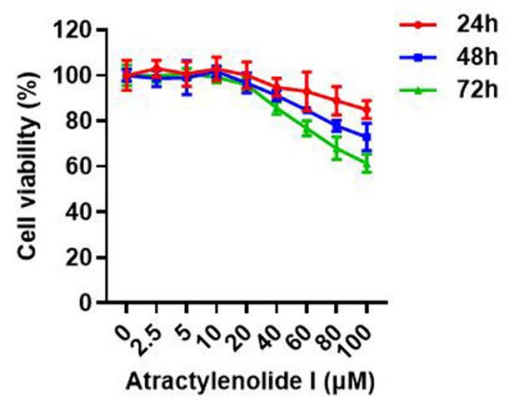

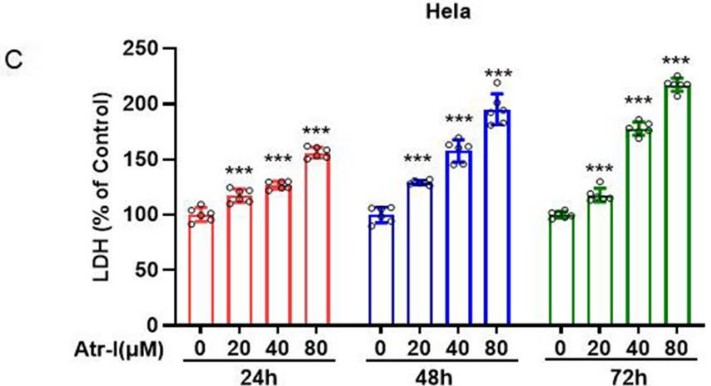

Atr-1 $(\mu \mathrm{M})$

Hela

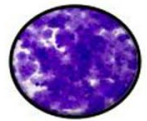

$\mathrm{SiHa}$

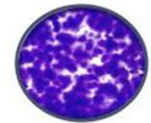

20
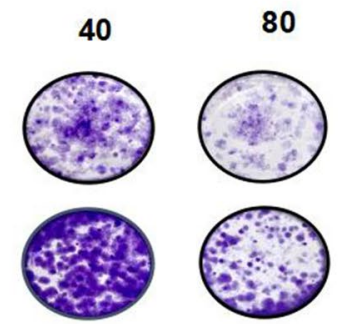

$F$

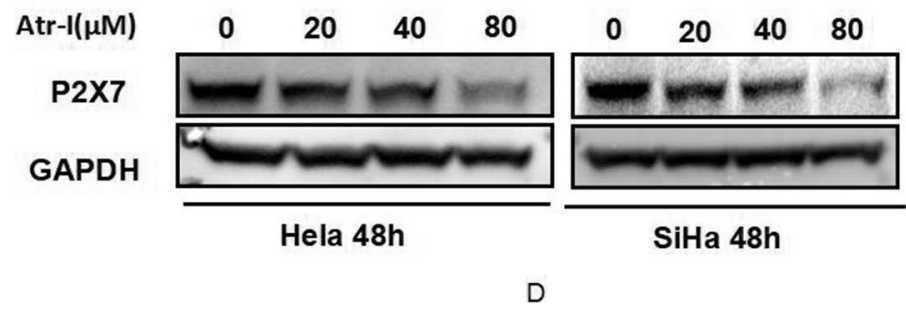

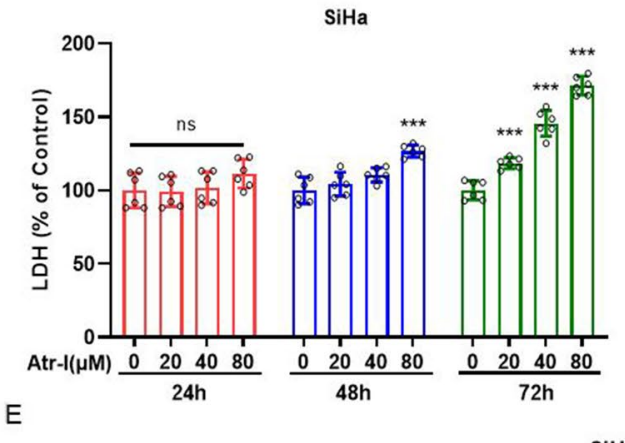
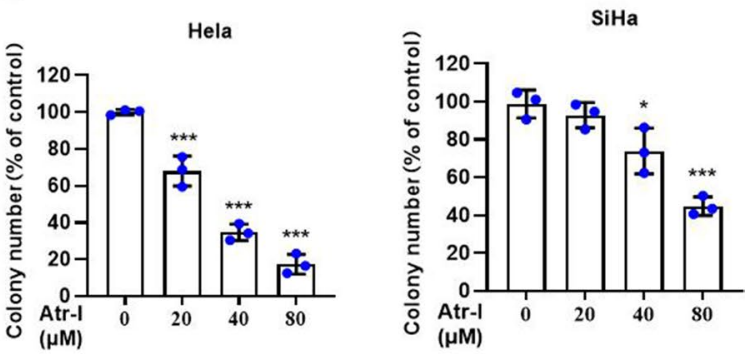

G

Hela 48h

$\mathrm{SiHa} 48 \mathrm{~h}$

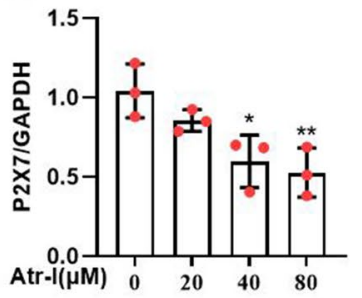

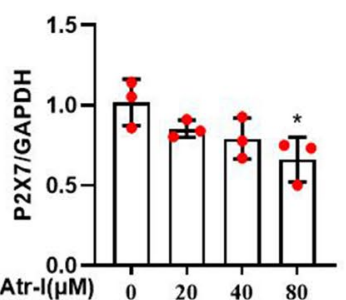

Fig. 1 Atractylenolide I inhibits human cervical cancer cells' proliferation in vitro. (A) Chemical structure of atractylenolide I. (B) The CCK8 assay of Hela cells and $\mathrm{SiHa}$ cells treated with the designed concentration of atractylenolide I for $24 \mathrm{~h}, 48 \mathrm{~h}$, and $72 \mathrm{~h}$. (C) LDH release assay in cells after exposure to increased atractylenolide I concentration for $24 \mathrm{~h}, 48 \mathrm{~h}$, and $72 \mathrm{~h}$. The colony formation assay of Hela cells and $\mathrm{SiHa}$ cells incubated with the increased atractyle-

diagnosed. The surgical or radiotherapeutic-treated cases still suffer from recurrence or metastasis, which give rise to poor clinical outcomes and prognosis [3-5]. It is still a big challenge to find out new promising target or potential new drug for the treatment of cervical cancer $[6,7]$. nolide I concentration for 2 weeks. The characteristic images (D) and the quantification of colonies $(\mathbf{E})$. (F) The protein of P2X7R in Hela cells and SiHa cells was detected by Western blot after $48 \mathrm{~h}$ of the treatment with atractylenolide I and the quantification of the protein of P2X7R $(\mathbf{G})$. All data are means $\pm \mathrm{SD}$. ${ }^{*} p<0.05$, $* * p<0.01, * * * p<0.001$ as compared with the atractylenolide I-untreated group

In recent years, purinergic signaling has been recognized to be a promising target in a variety of diseases in the whole body [8-10] since it was proposed by Burnstock in 1972 [11]. In the purinergic system, growing evidence supported that purinergic P2X7Rs play important role in different cancers, including lung cancer, colorectal cancer, 
breast cancer, and acute myeloid leukemia [12-19]. Apart from the strategy targeting the P2X7 ion channel, from antibodies and nanobodies to small-molecule drugs, which has been proved to improve the outcomes in models of cancer [20-24], the nature product is also taken into account for the development of potential anti-cancer drug to target purinergic receptors $[25,26]$. Atractylenolide I (Atr-I, Fig. 1A), a natural product extracted from Atractylodes macrocephala Koidz, was found to sensitize human colorectal cancer cells, ovarian cancer cells, breast cancer, gastric cancer, and bladder cancer cells in previous studies [27-34]. However, whether Atr-I would be able to raise antitumor activity in human cervical cancer or P2X7 receptors would be involved in the antitumor activity of Atr-I remains unclear. Hence, this study aims to obtain the in vitro evidence of antitumor activity and the role of P2X7 receptors in Atr-I-treated human cervical cancer cells.

\section{Materials and methods}

\section{Cell culture}

Human cervical cancer cell lines (Hela, HPV 18+; SiHa, HPV 16+) were obtained from the ATCC and cultured in DMEM supplemented with $10 \%$ fetal bovine serum (Thermo Fisher Scientific, USA), 100U/ml penicillin (Thermo Fisher Scientific, USA), and 100U/ml streptomycin (Thermo Fisher Scientific, USA), at $37^{\circ} \mathrm{C}$ in $5 \% \mathrm{CO}_{2}$.

\section{Antibodies and reagents}

Antibodies were purchased from Proteintech (GAPDH Monoclonal antibody 60,004-1-Ig, HRP-conjugated Affinipure Goat Anti-Rabbit IgG (H+L) SA00001-2, HRP-conjugated Affinipure Goat Anti-Mouse $\operatorname{IgG}(\mathrm{H}+\mathrm{L})$ SA00001-1) or Abcam (P2X7R ab93354, UK). The specific agonist to P2X7R, 2'(3')-O-(4-benzoylbenzoyl) adenosine 5'-triphosphate (BzATP, B6396) was purchased from Sigma. The selective P2X7 antagonist JNJ-47965567 (JNJ) was purchased from Tocris Bioscience (Bristol, UK). Atr-I (73,069-13-3) was purchased from Herbpurify (Chengdu, China).

\section{Cell proliferation inhibition test}

Cell Counting Kit-8 (CCK-8, AbMole, USA) and colony formation assays were used to detect cell proliferation. Briefly, the cells used for CCK- 8 assay were inoculated $\left(1 \times 10^{6}\right.$ cells $\left./ \mathrm{ml}\right)$ into a 96 -well plate, followed by the addition of $100 \mu \mathrm{l}$ of cell suspension to each well and received the designed concentrations of drug treatment. The detailed procedures have been described by Bai et al. [35]. The cells for colony formation assay were cultured in 24-well plates ( 800 cells/well) and incubated with the designed treatments. After 2 weeks, the $4 \%$ paraformaldehyde was adopted for fixation and crystal violet was used for staining. The visible colonies were calculated applying ImageJ software.

\section{Western blot analysis}

Cells were lysed in ice with RIPA buffer $(150 \mathrm{mmol} / \mathrm{l}$ Tris- $\mathrm{HCl} \mathrm{pH} 7.0,150 \mathrm{mmol} / \mathrm{l} \mathrm{NaCl}, 1 \% \mathrm{NP}-40,1 \%$ sodium deoxycholate, $0.1 \% \mathrm{SDS}$ ) containing with protease inhibitor cocktail (Roche, 4,693,159,001) for $30 \mathrm{~min}$. The Bio-Rad protein assay was used to quantify the lysates. The protein samples were subjected to NuPAGETM $10 \%$ Bis-Tris Protein Gels (Invitrogen, NP0302BOX) and probed with the indicated antibodies to visualize the protein levels using a ChemiScope 6000 Touch.

\section{Lactate dehydrogenase release assay}

Lactate dehydrogenase (LDH) test kit (Beyotime Biotechnology, Shanghai, China) was used to assess the cytotoxicity of atractylenolide I and in combination with or without $100 \mu \mathrm{M}$ BzATP or $20 \mu \mathrm{M}$ JNJ. Cells were cultured in 96 -well plates $\left(6 \times 10^{3}\right.$ cells/well $)$. After treatment with the designed concentrations of drugs, cell culture supernatant was transferred to the new 96-well plate for LDH analysis.

\section{Flow cytometry}

The ratio of apoptotic cells was measured with an Annexin V-AF647/PI Apoptosis Kit (E-CK-A213; Elabscience biotechnology, Wuhan, China) according to the manufacturer's instructions. Cells were harvested and washed twice with PBS and then resuspended in $500 \mu \mathrm{l}$ binding buffer. After adding $5 \mu \mathrm{l}$ annexinV-AF647 and $5 \mu \mathrm{PI}$ into the cell suspension, respectively, at least 20,000 live cells were analyzed on a FACSCalibur flow cytometer (BD Biosciences, San Jose, CA, USA). Data were analyzed by using FlowJo software (FlowJo, Ashland, OR, USA).

\section{Statistical analysis}

All experiments were performed at least three times independently. All statistical analysis and graphics were performed using GraphPad Prism 7.0 Software (GraphPad Software Inc., San Diego, CA). For two-group comparisons, Student's two-tailed $t$-test was used. For multiple 


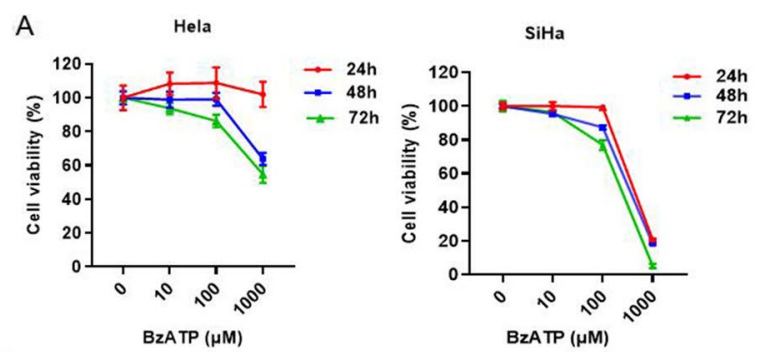

B

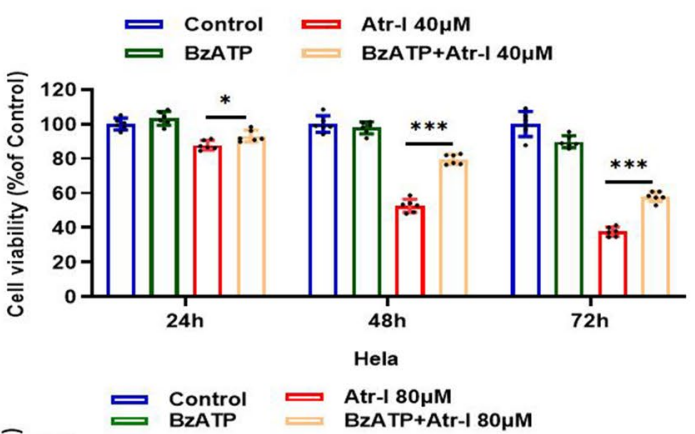

C

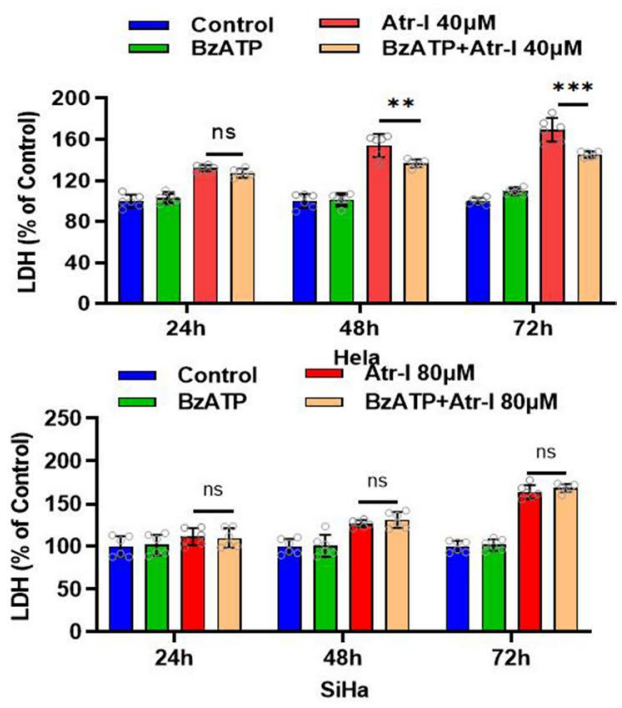

D
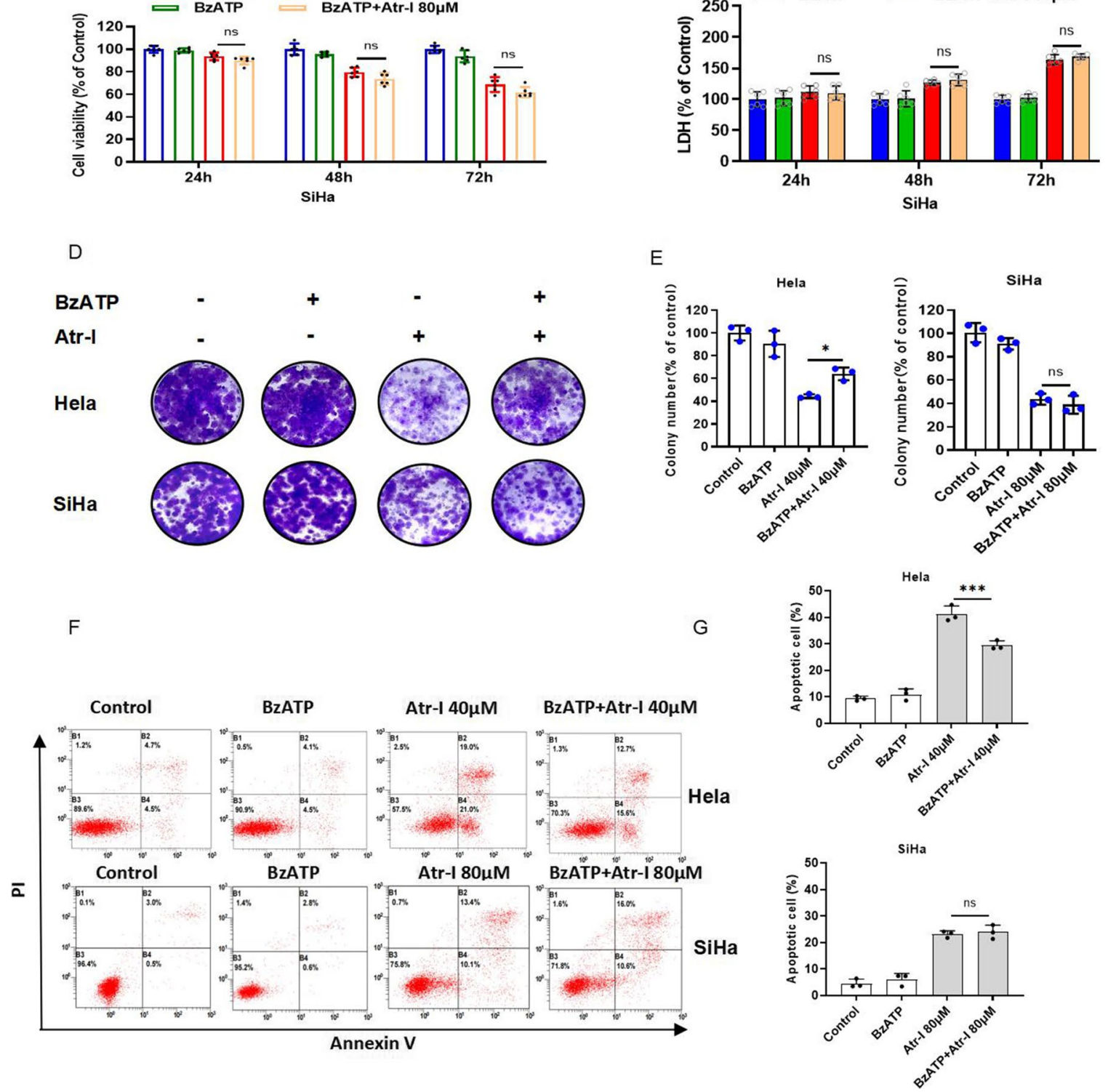
4Fig. 2 Activation of P2X7R affects cervical carcinoma cells' proliferation. (A) The CCK8 assay of Hela cells and SiHa cells treated with the designed concentration of BzATP for $24 \mathrm{~h}, 48 \mathrm{~h}$, and $72 \mathrm{~h}$. (B) CCK8 assay of Hela cells and $\mathrm{SiHa}$ cells indicated the presence or absence of atractylenolide I and in combination with or without $100 \mu \mathrm{M}$ BzATP for $24 \mathrm{~h}, 48 \mathrm{~h}$, and $72 \mathrm{~h}$. (C) LDH release assay in cells treated as in B. The colony formation assay in cells incubated under these same conditions for 2 weeks. The characteristic images (D) and the quantification of colonies $(\mathbf{E})$. (F, G) Hela cells and $\mathrm{SiHa}$ cells treated with atractylenolide I or $100 \mu \mathrm{M}$ BzATP alone or their mixture for $48 \mathrm{~h}$ were subjected to flow cytometry analysis. All data are means \pm SD. $* p<0.05, * * p<0.01, * * * p<0.001$

group comparisons, one-way ANOVA was used. A value of $P<0.05$ was considered statistically significant.

\section{Results}

\section{Atractylenolide I represses human cervical cancer cells' growthin vitro}

To evaluate whether Atr-I exhibits an antitumor effect against human cervical cancer cells, Hela cells and $\mathrm{SiHa}$ cells were treated with different doses of Atr-I. CCK8 assay showed that Atr-I markedly inhibited the growth of Hela cells and SiHa cells in a dose- and time-dependent manner. Notably, Hela cells were highly sensitive to Atr-I, whereas SiHa cells demonstrated higher tolerance to Atr-I (Fig. 1B). Consistently, the proliferation of Hela cells was significantly inhibited than that of SiHa cells in response to Atr-I treatment, as evidenced by reduced colony formation (Fig. 1D, E). Then, we performed LDH release assay and found that Atr-I damaged the integrity of the plasma membrane, which was most obvious at $72 \mathrm{~h}$ after treatment (Fig. 1C). Taken together, these results suggest that Atr-I demonstrate a considerable antitumor effect in human cervical cancer cells in vitro.

\section{The antitumor activity of atractylenolide I involves the $\mathrm{P} 2 \mathrm{X7}$ receptor in human cervical cancer cells}

Next, we intended to evaluate whether $\mathrm{P} 2 \mathrm{X} 7$ receptor was involved in the anti-human cervical cancer cells' effect of Atr-I. Firstly, the western blot analysis indicated that the decreased expression of $\mathrm{P} 2 \mathrm{X} 7$ receptor protein was observed in Atr-I-treated Hela cells and SiHa cells (Fig. 1F, G). And then, CCK8 assay showed that BzATP, the selective agonist of $\mathrm{P} 2 \mathrm{X} 7$ receptor, and JNJ, a selective small-molecule antagonist of $\mathrm{P} 2 \mathrm{X} 7$ receptor, markedly inhibited the growth of Hela cells and SiHa cells with a dose- and time-dependent manner (Fig. 2A, Fig. 3A). Interestingly, SiHa cells are more sensitive to BzATP. When human cervical cancer cells were treated with BzATP or JNJ and Atr-I together, the data indicated that BzATP partially restored Atr-I-induced growth inhibition in Hela cells, but it was hardly affected in SiHa cells (Fig. 2B). Consistently, the LDH release of Hela cells was significantly inhibited in response to combinational treatment of BzATP (Fig. 2C), as evidenced by increased colony formation (Fig. 2D, E). Whereas the combinatorial treatment of JNJ and Atr-I has an additive effect on cell growth inhibition in SiHa and Hela cells (Fig. 3B). Consistently, the LDH release of SiHa cells was significantly elevated in response to combinational treatment of JNJ (Fig. 3C) after 48 h, as evidenced by reduced colony formation (Fig. 3D, E). Finally, the data from flow cytometry presented that BzATP partially restored Atr-I-induced apotosis in Hela cells but not in SiHa cells (Fig. 2F, G). Whereas the combinatorial treatment of JNJ and Atr-I, JNJ partially promoted Atr-I-induced apotosis in SiHa cells but not in Hela cells (Fig. 3F, G). Taken together, these results implied that the $\mathrm{P} 2 \mathrm{X} 7$ receptor was involved in the anti-human cervical cancer cells effect of Atr-I with different roles in HeLa cells and $\mathrm{SiHa}$ cells.

\section{Discussion}

In this study, we firstly found that Atr-I generated a considerable antitumor effect in 2 different HPV phenotypes of human cervical cancer cell lines (Hela, HPV 18+; SiHa, HPV 16+) in vitro. It supports that Atr-I would be a potential promising anti-cancer compound for the treatment of human cervical cancer, especially caused by HPV 18 and HPV 16, as well as colorectal, ovarian, breast, gastric, and bladder cancers [27-34]. However, due to the fact that in the current study Hela cells were highly sensitive to Atr-I, whereas SiHa cells demonstrated higher tolerance to AtraI, it implied that we cannot neglect that the different cell lines would be the reason to present different responses to Atr-I treatment. Additional cell lines of human cervical cancer, including Bu25TK, CaSki, MS751, C33A, Me180, and HT-3, or in vivo data is needed to confirm the antitumor effect of Atr-I.

Based on current data, it seems that the role of purinergic P2X7R in the antitumor effect of Atr-I is diversity. The reduced protein expression of $\mathrm{P} 2 \mathrm{X} 7$ receptor in both Hela and SiHa cells was observed in this study. It implied that P2X7R might be able to get involved in the antitumor mechanism of Atr-I in 2 different human cervical cell lines. In Hela cells, co-application of P2X7 agonist BzATP and Atr-I led to the decreased antitumor effect whereas no changes were found under the condition combination of P2X7 antagonist JNJ and Atr-I. It suggested that the antitumor effect of Atr-I in Hela cells with HPV 18 positive would be linked with P2X7 receptor. However, it would be another possibility in SiHa cells with HPV 16 positive. Co-administration 

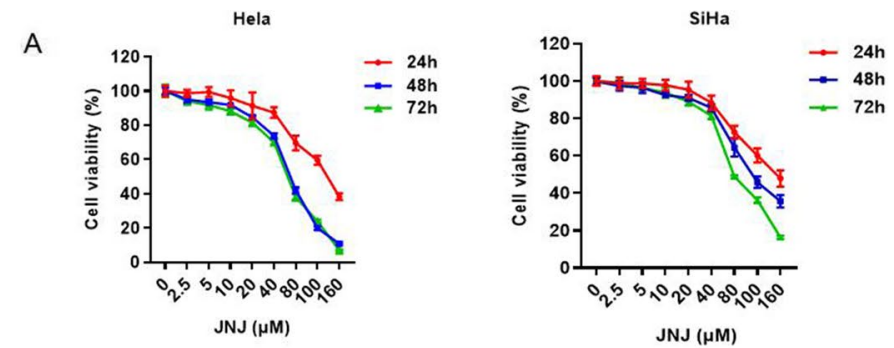

B

C
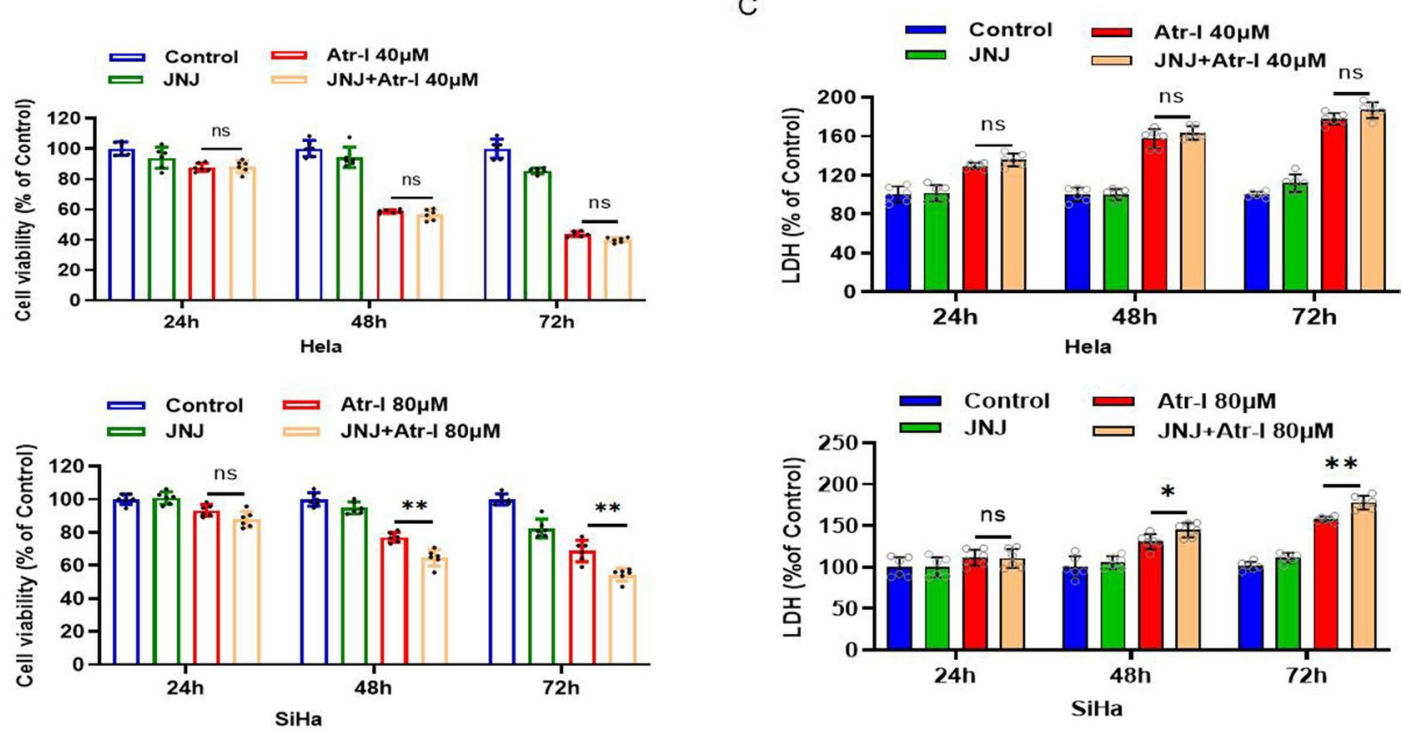

D

E
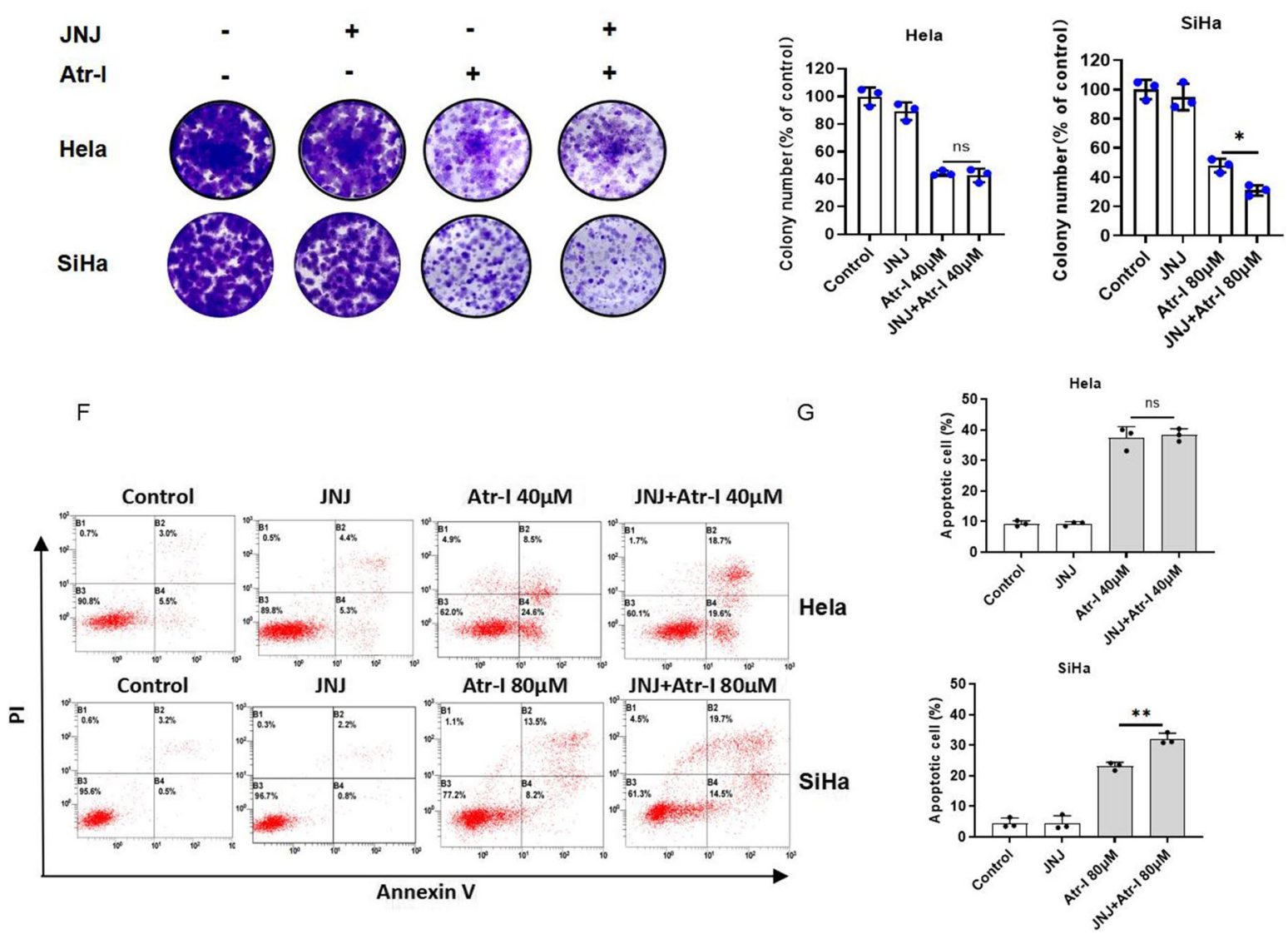
४Fig. 3 Inhibition of P2X7R affects cervical carcinoma cells' proliferation. (A) The CCK8 assay of Hela cells and SiHa cells treated with the designed concentration of JNJ for $24 \mathrm{~h}, 48 \mathrm{~h}$, and $72 \mathrm{~h}$. (B) CCK8 assay of Hela cells and $\mathrm{SiHa}$ cells indicated the presence or absence of atractylenolide I and in combination with or without $20 \mu \mathrm{M} \mathrm{JNJ}$ for $24 \mathrm{~h}, 48 \mathrm{~h}$, and $72 \mathrm{~h}$. (C) LDH release assay in cells treated as in B. The colony formation assay in cells incubated under these same conditions for 2 weeks. The characteristic images (D) and the quantification of colonies $(\mathbf{E})$. (F, G) Hela cells and $\mathrm{SiHa}$ cells treated with atractylenolide I or $20 \mu \mathrm{M}$ JNJ alone or their mixture for $48 \mathrm{~h}$ were subjected to flow cytometry analysis. All data are means \pm SD. $* p<0.05, * * p<0.01, * * * p<0.001$

of P2X7 antagonist JNJ rather than the agonist BzATP and Atr-I raised the antitumor effect although the single use of both agonist of P2X7 BzATP and the antagonist JNJ could generate antitumor effect in Hela and Siha cells. It could be proposed that the antitumor effect of Atr-I in Siha cells would be associated with purinergic $\mathrm{P} 2 \mathrm{X} 7$ receptors and its downstream pathway (PI3K/Akt/GSK-3 $\beta$, AKT, AMPKPRAS-40-mTOR, NOD-like receptor containing a pyrin inflammasome, etc.) which is regarded as the underlying mechanism of $\mathrm{P} 2 \mathrm{X} 7$ receptors in cancers [36-39].

It is worth pointing out that in our study both BzATP and JNJ have antitumor effect in Hela and SiHa cells. BzATP is the agonist to active $\mathrm{P} 2 \mathrm{X} 7$ receptor, theoretically which would be harmful for the treatment of cancer in that increasing evidence demonstrated that suppression of high concentration of ATP in tumor microenvironment and the activation of $\mathrm{P} 2 \mathrm{X} 7$ is recognized as a promising strategy for the treatment of different tumors [12, 18, 20, 38, 39]. However, ATP is considered a double-edged sword in cancer [40, 41] and BzATP could inhibit breast cancer cell migration [42]. It indicated that both the agonist (BzATP) and antagonist (JNJ) of P2X7 receptor would be useful to inhibit the proliferation of human cervical cancer. Maybe the reason would be related to the complicated regulation of downstream signaling pathways by $\mathrm{P} 2 \mathrm{X} 7$, including the concentration and duration of agonist exposure, the interaction of P2X7 with other receptors, and the interaction with the actin cytoskeleton machinery [38, 39, 43-45]. On the other hand, co-administration of $\mathrm{P} 2 \mathrm{X} 7$ antagonist JNJ rather than the agonist BzATP and Atr-I raised the antitumor effect, which might be derived from the complicated microenvironment of human cervical cancer. More comprehensive evidence would be pursued in the future design and research.

\section{Conclusions}

This study demonstrated that both the agonist and antagonist of P2X7 receptors, BzATP and JNJ, could suppress the proliferation of Hela and SiHa cells. And the P2X7 receptor would get involved in the antitumor effect of Atr-I in the 2 different human cervical cancer cell lines (HPV $18+$ in hela and HPV $16+$ in $\mathrm{SiHa}$ ) with different HPV phenotypes.

Funding This work is supported by the grants from NSFC (82074478), Jiangsu Provincial Hospital of Chinese Medicine (Y2020CX39), and Acupuncture \& Chronobiology Key Laboratory of Sichuan Province (No. 2021001).

Data availability The datasets generated during and/or analyzed during the current study are available from the corresponding author on reasonable request.

\section{Declarations}

Ethical approval All applicable international, national, and/or institutional guidelines for the care and use of animals were followed. This article does not contain any studies with human participants performed by any of the authors.

Conflicts of interest The authors declare no competing interests.

Open Access This article is licensed under a Creative Commons Attribution 4.0 International License, which permits use, sharing, adaptation, distribution and reproduction in any medium or format, as long as you give appropriate credit to the original author(s) and the source, provide a link to the Creative Commons licence, and indicate if changes were made. The images or other third party material in this article are included in the article's Creative Commons licence, unless indicated otherwise in a credit line to the material. If material is not included in the article's Creative Commons licence and your intended use is not permitted by statutory regulation or exceeds the permitted use, you will need to obtain permission directly from the copyright holder. To view a copy of this licence, visit http://creativecommons.org/licenses/by/4.0/.

\section{References}

1. Sung H, Ferlay J, Siegel RL et al (2021) Global Cancer Statistics 2020: GLOBOCAN Estimates of Incidence and Mortality Worldwide for 36 Cancers in 185 Countries. CA Cancer J Clin 71(3):209-249. https://doi.org/10.3322/caac.21660

2. https://www.who.int/news-room/fact-sheets/detail/cervical-cancer

3. Melnikow J, Henderson JT, Burda BU, Senger CA, Durbin S, Weyrich MS (2018) Screening for cervical cancer with high-risk human papillomavirus testing: Updated evidence report and systematic review for the US preventive services task force. JAMA 320(7):687-705. https://doi.org/10.1001/jama.2018.10400

4. Nama V, Angelopoulos G, Twigg J, Murdoch JB, Bailey J, Lawrie TA (2018) Type II or type III radical hysterectomy compared to chemoradiotherapy as a primary intervention for stage IB2 cervical cancer. Cochrane Database Syst Rev 10(10):CD011478. https://doi.org/10.1002/14651858.CD011478.pub2

5. Simms KT, Steinberg J, Caruana M et al (2019) Impact of scaled up human papillomavirus vaccination and cervical screening and the potential for global elimination of cervical cancer in 181 countries, 2020-99: a modelling study. Lancet Oncol 20(3):394-407. https://doi.org/10.1016/S1470-2045(18)30836-2

6. Wendel Naumann R, Leath CA 3rd (2020) Advances in immunotherapy for cervical cancer. Curr Opin Oncol 32(5):481-487. https://doi.org/10.1097/CCO.0000000000000663 
7. Sharma S, Deep A, Sharma AK (2020) Current Treatment for Cervical Cancer: An Update. Anticancer Agents Med Chem 20(15):1768-1779. https://doi.org/10.2174/187152062066620 0224093301

8. Burnstock $\mathrm{G}$ (2018) The therapeutic potential of purinergic signalling. Biochem Pharmacol 151:157-165. https://doi.org/10.1016/j. bcp.2017.07.016

9. Burnstock G (2017) Purinergic Signalling: Therapeutic Developments Front Pharmacol 8:661. https://doi.org/10.3389/fphar.2017. 00661

10. Huang Z, Xie N, Illes P et al (2021) From purines to purinergic signalling: molecular functions and human diseases. Signal Transduct Target Ther 6(1):162. https://doi.org/10.1038/ s41392-021-00553-z

11. Burnstock G (1972) Purinergic nerves. Pharmacol Rev 24(3):509-581

12. Di Virgilio F, Sarti AC, Falzoni S, De Marchi E, Adinolfi E (2018) Extracellular ATP and P2 purinergic signalling in the tumour microenvironment. Nat Rev Cancer 18(10):601-618. https://doi. org/10.1038/s41568-018-0037-0

13. Li Q, Zhu X, Song W, Peng X, Zhao R (2020) The P2X7 purinergic receptor: a potential therapeutic target for lung cancer. J Cancer Res Clin Oncol 146(11):2731-2741. https://doi.org/10.1007/ s00432-020-03379-4

14. Calik I, Calik M, Turken G, Ozercan IH (2020) A promising independent prognostic biomarker in colorectal cancer: $\mathrm{P} 2 \mathrm{X} 7$ receptor. Int J Clin Exp Pathol 13(2):107-121

15. Calik I, Calik M, Sarikaya B, Ozercan IH, Arslan R, Artas G, Dagli AF (2020) P2X7 receptor as an independent prognostic indicator in gastric cancer. Bosn J Basic Med Sci 20(2):188-196. https://doi.org/10.17305/bjbms.2020.4620

16. Zhang Y, Ding J, Wang L (2019) The role of P2X7 receptor in prognosis and metastasis of colorectal cancer. Adv Med Sci 64(2):388-394. https://doi.org/10.1016/j.advms.2019.05.002

17. Zheng L, Zhang X, Yang F, Zhu J, Zhou P, Yu F, Hou L, Xiao L, He Q, Wang B (2014) Regulation of the P2X7R by microRNA$216 \mathrm{~b}$ in human breast cancer. Biochem Biophys Res Commun 452(1):197-204. https://doi.org/10.1016/j.bbrc.2014.07.101

18. Vultaggio-Poma V, Sarti AC, Di Virgilio F (2020) Extracellular ATP: A Feasible Target for Cancer Therapy. Cells 9(11):2496. https://doi.org/10.3390/cells9112496

19. Pegoraro A, Adinolfi E (2021) The ATP/P2X7 axis is a crucial regulator of leukemic initiating cells proliferation and homing and an emerging therapeutic target in acute myeloid leukemia. Purinergic Signalling 17:319-321. https://doi.org/10.1007/ s11302-021-09789-4

20. Burnstock, G., Knight, G.E. The potential of P2X7 receptors as a therapeutic target, including inflammation and tumour progression. Purinergic Signalling.2018;1-18. https://doi.org/10.1007/ s11302-017-9593-0

21. Zhang WJ, Hu CG, Zhu ZM, Luo HL (2020) Effect of P2X7 receptor on tumorigenesis and its pharmacological properties. Biomed Pharmacother 125:109844. https://doi.org/10.1016/j. biopha.2020.109844

22. Koch-Nolte F, Eichhoff A, Pinto-Espinoza C et al (2019) Novel biologics targeting the P2X7 ion channel. Curr Opin Pharmacol 47:110-118. https://doi.org/10.1016/j.coph.2019.03.001

23. Sarti AC, Vultaggio-Poma V. \& Di Virgilio F. P2X7: a receptor with a split personality that raises new hopes for anti-cancer therapy. Purinergic Signalling.2021;175-178. doi.org/https://doi. org/10.1007/s11302-021-09783-w

24. Douguet L, Janho Dit Hreich S, Benzaquen J, et al. A small-molecule P2RX7 activator promotes anti-tumor immune responses and sensitizes lung tumor to immunotherapy. Nat Commun. 2021;12(1):653. https://doi.org/10.1038/s41467-021-20912-2
25. Jelassi B, Anchelin M, Chamouton J et al (2013) Anthraquinone emodin inhibits human cancer cell invasiveness by antagonizing P2X7 receptors. Carcinogenesis 34(7):1487-1496. https://doi.org/ 10.1093/carcin/bgt099

26. Ai X, Dong X, Guo Y et al (2021) Targeting P2 receptors in purinergic signaling: a new strategy of active ingredients in traditional Chinese herbals for diseases treatment. Purinergic Signal 17(2):229-240. https://doi.org/10.1007/s11302-021-09774-x

27. Wang K, Huang W, Sang X et al (2020) Atractylenolide I inhibits colorectal cancer cell proliferation by affecting metabolism and stemness via AKT/mTOR signaling. Phytomedicine 68:153191. https://doi.org/10.1016/j.phymed.2020.153191

28. Long F, Lin H, Zhang X, Zhang J, Xiao H, Wang T (2020) Atractylenolide-I Suppresses Tumorigenesis of Breast Cancer by Inhibiting Toll-Like Receptor 4-Mediated Nuclear Factor- $\kappa \mathrm{B}$ Signaling Pathway. Front Pharmacol 11:598939. https://doi.org/ 10.3389/fphar.2020.598939

29. Wang K, Huang W, Sang X, Wu X, Shan Q, Tang D, Xu X, Cao G (2020) Atractylenolide I inhibits colorectal cancer cell proliferation by affecting metabolism and stemness via AKT/mTOR signaling. Phytomedicine 68:153191. https://doi.org/10.1016/j. phymed.2020.153191

30. Li Y, Wang Y, Liu Z, Guo X, Miao Z, Ma S (2020) Atractylenolide I Induces Apoptosis and Suppresses Glycolysis by Blocking the JAK2/STAT3 Signaling Pathway in Colorectal Cancer Cells. Front Pharmacol 11:273. https://doi.org/10.3389/fphar. 2020.00273

31. Long F, Wang T, Jia P, Wang H, Qing Y, Xiong T, He M, Wang X (2017) Anti-Tumor Effects of Atractylenolide-I on Human Ovarian Cancer Cells. Med Sci Monit 23:571-579. https://doi.org/10. 12659/msm.902886

32. Ma L, Mao R, Shen K, Zheng Y, Li Y, Liu J, Ni L (2014) Atractylenolide I-mediated Notch pathway inhibition attenuates gastric cancer stem cell traits. Biochem Biophys Res Commun 450(1):353-359. https://doi.org/10.1016/j.bbrc.2014.05.110

33. Yu R, Yu BX, Chen JF, Lv XY, Yan ZJ, Cheng Y, Ma Q (2016) Anti-tumor effects of Atractylenolide I on bladder cancer cells. J Exp Clin Cancer Res 35:40. https://doi.org/10.1186/ s13046-016-0312-4

34. Chan KWK, Chung HY, Ho WS (2020) Anti-Tumor Activity of Atractylenolide I in Human Colon Adenocarcinoma In Vitro. Molecules 25(1):212. https://doi.org/10.3390/molecules25010212

35. Bai C Zhang Z Zhou L Zhang HY Chen Y Tang Y. Repurposing Ziyuglycoside II Against Colorectal Cancer via Orchestrating Apoptosis and Autophagy. Front Pharmacol. 2020. https://doi. org/10.3389/fphar.2020.576547

36. Zhang WJ, Luo C, Huang C, Pu FQ, Zhu JF, Zhu ZM (2021) $\mathrm{PI} 3 \mathrm{~K} / \mathrm{Akt} / \mathrm{GSK}-3 \beta$ signal pathway is involved in $\mathrm{P} 2 \mathrm{X} 7$ receptorinduced proliferation and EMT of colorectal cancer cells. Eur J Pharmacol 899:174041. https://doi.org/10.1016/j.ejphar.2021. 174041

37. Zhu X, Li Q, Song W, Peng X, Zhao R (2021) P2X7 receptor: a critical regulator and potential target for breast cancer. J Mol Med (Berl) 99(3):349-358. https://doi.org/10.1007/ s00109-021-02041-x

38. Lara R, Adinolfi E, Harwood CA et al (2020) P2X7 in Cancer: From Molecular Mechanisms to Therapeutics. Front Pharmacol 11:793. https://doi.org/10.3389/fphar.2020.00793

39. Bian S, Sun X, Bai A et al (2013) P2X7 integrates PI3K/AKT and AMPK-PRAS40-mTOR signaling pathways to mediate tumor cell death. PLoS One 8(4):e60184. https://doi.org/10.1371/journ al.pone. 0060184

40. Jiang JX, Riquelme MA, Zhou JZ (2015) ATP, a double-edged sword in cancer. Oncoscience 2(8):673-674. https://doi.org/10. 18632/oncoscience.230 
41. Zhou JZ, Riquelme MA, Gao X, Ellies LG, Sun LZ, Jiang JX (2015) Differential impact of adenosine nucleotides released by osteocytes on breast cancer growth and bone metastasis. Oncogene 34(14):1831-1842. https://doi.org/10.1038/onc.2014.113

42. Liu X, Riquelme MA, Tian Y et al (2021) ATP Inhibits breast cancer migration and bone metastasis through down-regulation of CXCR4 and purinergic receptor P2Y11. Cancers (Basel) 13(17):4293. https://doi.org/10.3390/cancers13174293

43. Kim M, Jiang LH, Wilson HL, North RA, Surprenant A (2001) Proteomic and functional evidence for a $\mathrm{P} 2 \mathrm{X} 7$ receptor signalling complex. EMBO J 20(22):6347-6358. https://doi.org/10.1093/ emboj/20.22.6347

44. Gu BJ, Rathsam C, Stokes L, McGeachie AB, Wiley JS (2009) Extracellular ATP dissociates nonmuscle myosin from P2X(7) complex: this dissociation regulates $\mathrm{P} 2 \mathrm{X}(7)$ pore formation. Am J Physiol Cell Physiol 297(2):C430-C439. https://doi.org/10.1152/ ajpcell.00079.2009
45. Zhang Y, Cheng H, Li W, Wu H, Yang Y (2019) Highly-expressed $\mathrm{P} 2 \mathrm{X} 7$ receptor promotes growth and metastasis of human HOS/ MNNG osteosarcoma cells via PI3K/Akt/GSK3 $\beta / \beta$-catenin and mTOR/HIF1 $\alpha /$ VEGF signaling. Int J Cancer 145(4):1068-1082. https://doi.org/10.1002/ijc.32207

46. Yuan Y, Cai X, Shen F, Ma F (2021) HPV post-infection microenvironment and cervical cancer. Cancer Lett 497:243-254. https:// doi.org/10.1016/j.canlet.2020.10.034

47. Pfaffenzeller MS, Franciosi MLM, Cardoso AM (2020) Purinergic signaling and tumor microenvironment in cervical Cancer. Purinergic Signal 16(1):123-135. https://doi.org/10.1007/ s11302-020-09693-3

Publisher's note Springer Nature remains neutral with regard to jurisdictional claims in published maps and institutional affiliations. 